\title{
Analysis of torsional vibration effect on the diesel engine block vibration
}

\author{
Shiwei $\mathrm{Ni}^{1}$, Yibin Guo ${ }^{1, *}$, Binglin $\mathrm{Lv}^{2}$, Donghua Wang ${ }^{1}$, Wanyou $\mathrm{Li}^{1}$, and Zhijun Shuai ${ }^{1}$ \\ ${ }^{1}$ College of Power and Energy Engineering, Harbin Engineering University, Harbin Heilongjiang, China \\ ${ }^{2}$ China Shipbuilding Power Engineering Institute Co., Ltd, Shanghai, China
}

Received: 20 October 2019 / Accepted: 20 July 2020

\begin{abstract}
In this paper, the coupling effect between the crankshaft torsional vibration and the low speed diesel engine block vibration is investigated. Using finite element method (FEM), a model of low speed diesel engine is established to study the vibration response. The mode results of FEM agree very well with the test. The additional torques acting on the low-speed diesel engine caused by torsional vibration are discussed in detail. The vibration response of the low-speed diesel engine considering the effect of torsional vibration is studied using FEM simulation. By analyzing the effect of torsional vibration, the results demonstrate that the crankshaft torsional vibrations have important effects on the engine block vibration. The results from this study can provide useful theoretical guidance to predict vibration of low-speed diesel engine.
\end{abstract}

Keywords: Coupling model / torsional vibration / block vibration / FEM / low speed diesel engine

\section{Introduction}

Low-speed marine diesel engines are widely used in large ocean going vessels of over 2000 tons such as bulk freighter, container vessel and oil tanker and so on. With low speed and high power, they usually are running at rotation speed lower than $300 \mathrm{rev} / \mathrm{min}$. Along with increasing demand on comfort of working environment for sailors, especially in the cabin, IMO has set a higher standard for noise and vibration of cabin. As marine diesel engine is a largest source of vibration in the cabin, studying the marine diesel engine vibration becomes particularly important. There are a lot of available researchers involving in surface vibration of low-speed diesel engine. A study shows that the surface vibration of low-speed diesel engine is mainly caused by cylinder combustion pressure, crosshead side thrust and main bearing force [1]. The body vibration caused by the side thrust acting on the guide and the overturning moment formed by bearing horizontal force and the side thrust. The vibration by the overturning moment is greater than by the reciprocating inertia force [2]. Cho et al. calculated the block vibration by the crosshead side thrust through the test and the excitation [3].

Among the works of the coupling vibration between crankshaft and block, considering the coupling crankshaft dynamic and the main bearing lubrication, the force of crankshaft on the body was calculated by solving the Reynolds

\footnotetext{
* email: guoyibin@hrbeu.edu.cn
}

equation [4-6]. He et al. studied the effect of shaft vibration on the block by coupling the oil film lubrication model with FEM [7]. Xue et al. found that when the torsional vibration resonates, the block vibration increased evidently [8]. Liang measured the signals of crankshaft $3 \mathrm{D}$ vibration and the body vibration and analyzed the partial coherence between them. He found that the surface vibration of crankcase caused by the 3 -D vibration of the crankshaft [9]. In following research, they optimized the design of body vibration by changing different torsional vibration absorbers [10]. Some researchers studied the effect of the torsional vibration absorber on the block vibration combining FEM with the multibody system simulation method [11-13]. Li analyzed the form of excitation generated by torsional vibration on the block vibration and proposed some design scheme by optimizing crankshaft vibration to reduce the surface vibration [14].

For the simulation of body vibration in low-speed diesel engine, Inagaki et al. set up a software platform for the vibration analysis of internal combustion engine and it was verified by test [15]. Ma and Perkins also established a software platform to solve the vibration by analyzing dynamics of the body and moving parts [16]. For complex structures, using CAE to calculate the vibration response of the block can greatly shorten the computation time. Through the NVH analysis, it can predict the vibration of diesel engine and can provided a feasible revision plan for low-noise diesel engine design [17]. Cameron et al. used FEM to analyze the noise and vibration of vehicle block and demonstrated the advantage of FEM to study the complex structural vibration [18]. Ohta et al. proposed a coupling model between crankshaft and block to predict body vibration after obtaining the reciprocating 
inertial force, piston slap force and cylinder pressure $[19,20]$. Lee et al. considered the influence of speed oscillation in solving the crankshaft longitudinal-torsional coupled excitation. It provides more accurate method to simulate block vibration of diesel engine [21].

Up till now, a few published papers are involving in simulating block vibration of low-speed marine diesel engine, especially, not considering the coupled effect of shaft torsional vibration on block vibration. In this study, Firstly, A FEM model of studied low-speed marine diesel engine is created and is calibrated against a test. Secondly, the excitation forces on the low-speed engine vibration are derived. Next, the oscillation of loading position of crosshead side thrust due to the crankshaft torsional vibration is discussed. The additional torque caused by torsional vibration is obtained. Finally, the FEM simulation results of block vibration of considering the torsional vibration and the results of considering traditional excitation are compared with the test separately and the difference are discussed.

\section{Excitation force analysis}

\subsection{The basic parameters of diesel engine}

In this section, the vibration excitation forces of the low speed diesel engine are discussed in details. In traditional method, the vibration of diesel engine is excited by the cylinder combustion pressure, crosshead thrust, and main bearing reaction force. Using dynamic force analysis, all the excitation forces are obtained. Taking the first cylinder of low-speed diesel engine as an example, the dynamic analysis of moving parts of the first cylinder is shown in Figure 1. The parameters of the low speed diesel engine are shown in Table 1.

From the Figure 1, where $P_{g}$ is the cylinder pressure, $F_{j}$ is the reciprocating inertial force, $F_{T}$ is the tangential force on crank pin, $F_{N}$ is the normal force on crank pin and $F_{w}$ is the centrifugal force. $\Delta \omega$ is the oscillation of angular velocity. $\theta_{t o r}$ is fluctuation of twist angle which is called torsional vibration. $\beta$ is angle between connecting rod center and cylinder center. $\alpha=\omega t$ is angular displacement for mean speed. $\omega$ is the mean angular velocity. Similarly, the dynamic analysis of moving parts of the other cylinders can be obtained.

\subsection{Tangential force on crank pin}

For low-speed diesel marine engine, the tangential force on the crank pin is mainly composed by four parts: the cylinder pressure, the reciprocating inertia force, the weight of reciprocating components and the weight of rotating parts, separately. The cylinder pressure is obtained by the pressure sensors and is shown in Figure 2.

From Figure 1, the part of the tangential force of the $i$ th cylinder, which is caused by the cylinder pressure, the reciprocating inertia force and the weight of reciprocating components, separately, is given as:

$$
F_{T 1 i}=\sin \left(\alpha+\beta+\varphi_{i}\right)\left(F_{g i}+F_{j i}+F_{G_{j} i}\right)
$$

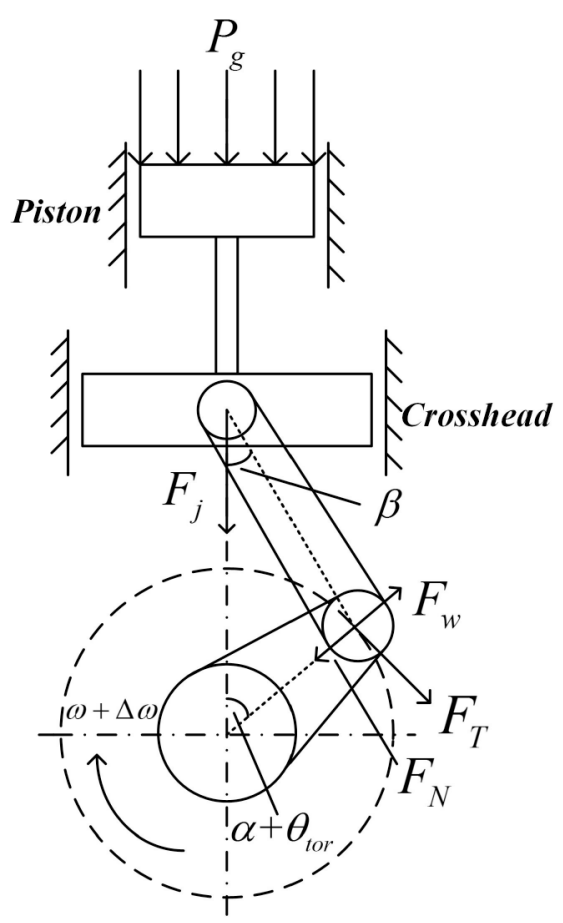

Fig. 1. Dynamic analysis of first cylinder.

Table 1. Parameters of low speed diesel engine.

\begin{tabular}{lrr}
\hline & Magnitude & Units \\
\hline Cylinder number & 6 & - \\
Speed & 99 & $\mathrm{rev} / \mathrm{min}$ \\
Piston diameter & 340 & $\mathrm{~mm}$ \\
Connecting rod length & 1600 & $\mathrm{~mm}$ \\
Crank radius & 500 & $\mathrm{~mm}$ \\
Reciprocating mass & 1144 & $\mathrm{~kg}$ \\
Connecting rod mass & 575 & $\mathrm{~kg}$ \\
Rotary mass & 1626 & $\mathrm{~kg}$ \\
Power & 1224 & $\mathrm{~kW}$ \\
Firing order & $1-6-2-4-3-5$ & \\
Stroke number & 2 & \\
\hline
\end{tabular}

where $F_{g i}=\frac{1}{4} \pi D^{2} P_{g i}$ is the force of the cylinder pressure on the piston. $\varphi_{i}$ is the initial phase of each cylinder. $F_{G_{i}}$ is weight of reciprocating components. $F_{j i}=-m_{j i} a_{j i}$ is the reciprocating inertia force. $a_{j i}$ is the reciprocating acceleration given as:

$$
a_{j i}=R \omega^{2}\left(\cos \left(\alpha+\varphi_{i}\right)+\lambda \cos 2\left(\alpha+\varphi_{i}\right)\right)
$$

$m_{j}$ is reciprocating mass. $i$ is different cylinder.

From Figure 1, the other part of the tangential force, which is caused by the weight of rotating moving parts, is given as:

$$
F_{T 2 i}=G_{w i} \sin \left(\alpha+\varphi_{i}\right)
$$




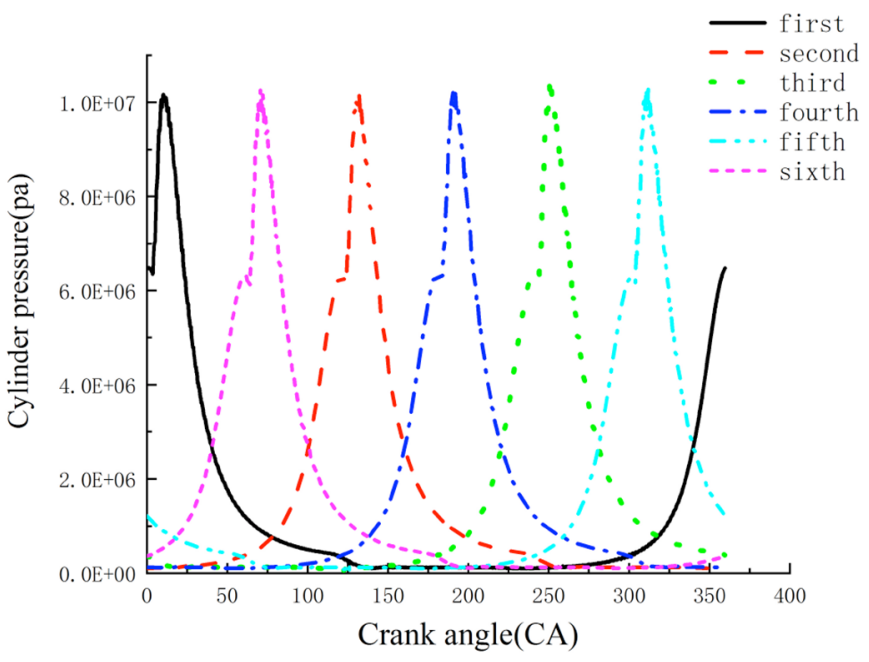

Fig. 2. Measured cylinder pressure.

where $G_{w}=\left(\frac{m_{r} l}{R}+(1-\xi) m_{c}\right) g$ is the weight of rotating moving parts. $m_{r}$ is the rotating partial mass of the crank and balance weight. $l$ is the distance between the center of the crank and the center of the weight of rotating part. $m_{c}$ is the mass of the connecting rod. $\xi$ is ratio of the distance of between the center of connecting rod weight and center of crank pin to the connecting rod. $R$ is the crankshaft radius.

\subsection{Normal force on crank pin}

Caused by the cylinder pressure, the reciprocating inertia force and the weight of reciprocating components, separately, the part of the normal force is given as:

$$
F_{N 1 i}=\cos \left(\alpha+\beta+\varphi_{i}\right)\left(F_{g i}+F_{j i}+F_{G_{j} i}\right)
$$

The other part of the normal force caused by the weight of rotating moving parts is given as:

$$
F_{N 2 i}=G_{w i} \cos \left(\alpha+\varphi_{i}\right)
$$

The centrifugal inertia force is given as:

$$
F_{w i}=m_{w i} R \omega^{2}
$$

where $m_{w}$ is the centrifugal mass.

\subsection{Side thrust of cross head}

The overturning moment, which is composed of the side thrust of cross head and the horizontal bearing force, is equal to the output moment caused by the tangential force in the value but opposite in the direction. Therefore, the side thrust is given as:

$$
F_{H i}=-\left(F_{T 1 i}+F_{T 2 i}\right) R / H_{i}
$$

where $H_{i}$ is the distance between the cross head and the center of the crankshaft. It can be expressed as:

$$
H_{i}=R \frac{\sin \left(\alpha+\varphi_{i}+\beta\right)}{\cos \beta}
$$

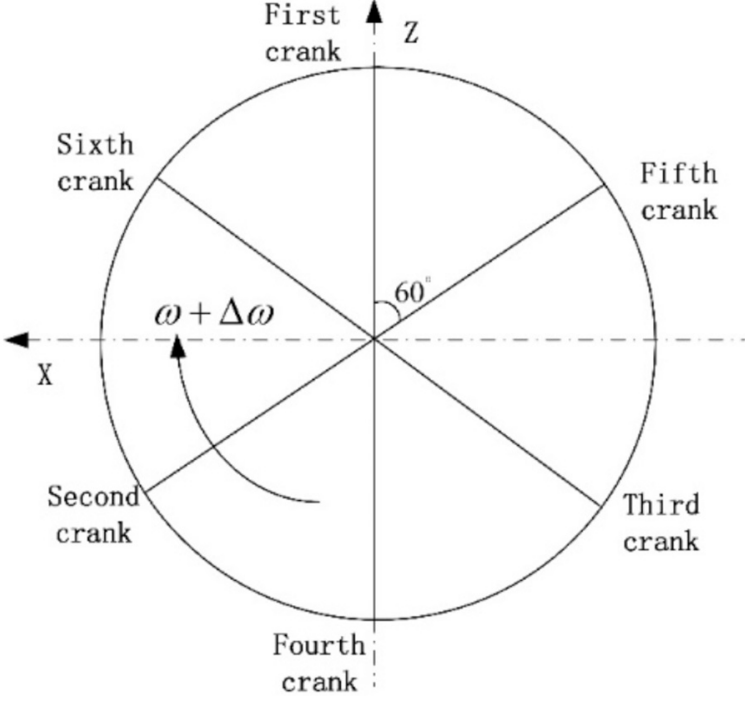

Fig. 3. Position of the crank cylinders relative to the first one.

where $L$ is the length of connecting rod and $R$ is the crankshaft radius.

\subsection{Main bearing reaction force}

The main bearing reaction force of a single cylinder is the vector sum of the tangential force and the normal force on crank pin. Hence, the main bearing reaction force can be given as:

$$
F_{w}=\sqrt{\left(F_{T 1 i}+F_{T 2 i}\right)^{2}+\left(F_{N 1 i}+F_{N 2 i}-F_{w i}\right)^{2}}
$$

For the low speed diesel engine of this research, there are seven bearings. Each bearing reaction force is the vector sum of bearing reaction forces from two adjacent cylinders except the end bearings which is only affected by the first cylinder and the sixth cylinder. The crank initial phase of low speed diesel engine is shown as Figure 3. Assuming that a clockwise phase is positive defined as advanced and a counterclockwise phase is negative defined as backward. From Figure 3, the phases of each cylinder relative to the first one are advanced. They are $0^{\circ}, 240^{\circ}, 120^{\circ}, 180^{\circ}, 60^{\circ}$ and $300^{\circ}$, separately.

To make applying forces easily, the bearing reaction force for middle bearings is decomposed into the horizontal one and the vertical one, respectively. They are:

$$
\begin{aligned}
F_{x j}= & -\frac{F_{T(j-1)}}{2} \sin \left(\alpha+\varphi_{j-1}+\frac{\pi}{2}\right)-\frac{F_{N(j-1)}}{2} \sin \left(\alpha+\varphi_{j-1}+\pi\right) \\
& -\frac{F_{T j}}{2} \sin \left(\alpha+\varphi_{j}+\frac{\pi}{2}\right)-\frac{F_{N j}}{2} \sin \left(\alpha+\varphi_{j}+\pi\right) \\
F_{z j}= & \frac{F_{T(j-1)}}{2} \cos \left(\alpha+\varphi_{j-1}+\frac{\pi}{2}\right)+\frac{F_{N(j-1)}}{2} \cos \left(\alpha+\varphi_{j-1}+\pi\right) \\
+ & \frac{F_{T j}}{2} \cos \left(\alpha+\varphi_{j}+\frac{\pi}{2}\right)+\frac{F_{N j}}{2} \cos \left(\alpha+\varphi_{j}+\pi\right)
\end{aligned}
$$




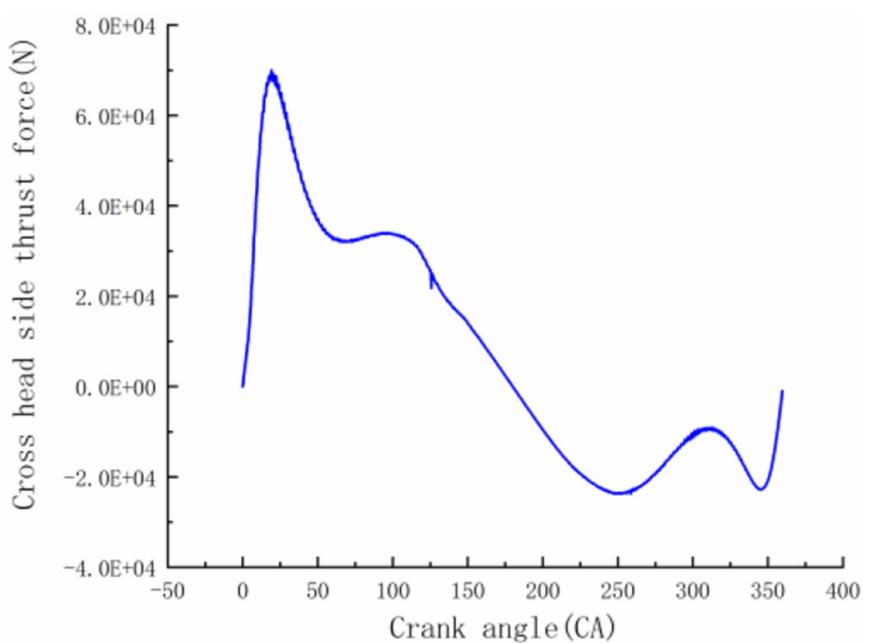

Fig. 4. Crosshead side thrust within single cycle.

where $\varphi_{j}$ is the phase of each cranks relative to the first one and $\varphi_{j}=\frac{4 \pi}{3}, \frac{2 \pi}{3}, \pi, \frac{\pi}{3}$, separately. $j$ is the bearing number. For the first bearing and the end bearing, the reaction force can be expressed as follows:

$$
\begin{aligned}
& F_{x k}=-\frac{F_{T k}}{2} \sin \left(\alpha+\varphi_{k}+\frac{\pi}{2}\right)-\frac{F_{N k}}{2} \sin \left(\alpha+\varphi_{k}+\pi\right) \\
& F_{z k}=\frac{F_{T k}}{2} \cos \left(\alpha+\varphi_{k}+\frac{\pi}{2}\right)+\frac{F_{N k}}{2} \cos \left(\alpha+\varphi_{k}+\pi\right)
\end{aligned}
$$

where $\varphi_{k}=0, \frac{5 \pi}{3}$, respectively.

\subsection{The excitation force results}

This section will discuss obtained excitation forces on the studied low speed diesel engine. For the traditional method, once the angular displacement for mean speed is given, all the forces are obtained from equations (1) - (8) without considering shaft torsional vibration. Using the first cylinder as an example, the result of crosshead side thrust is shown in Figure 4.

Using the first bearing as an example, the horizontal force and vertical force of main bearing force are obtained by equations $(9)-(11)$. The result in the calculation time are shown in Figure 5.

\section{Additional moment due to torsional vibration}

In this section further to understand how the crankshaft vibration affects the structure vibration of the engine, it investigated the oscillation of the loading position of side thrust.

Under the normal working condition of low speed diesel engine, the trajectory of crosshead shows a steady trend. But, if the torsional vibration occurred at crankshaft, the trajectory of the crosshead can be slightly up and down.
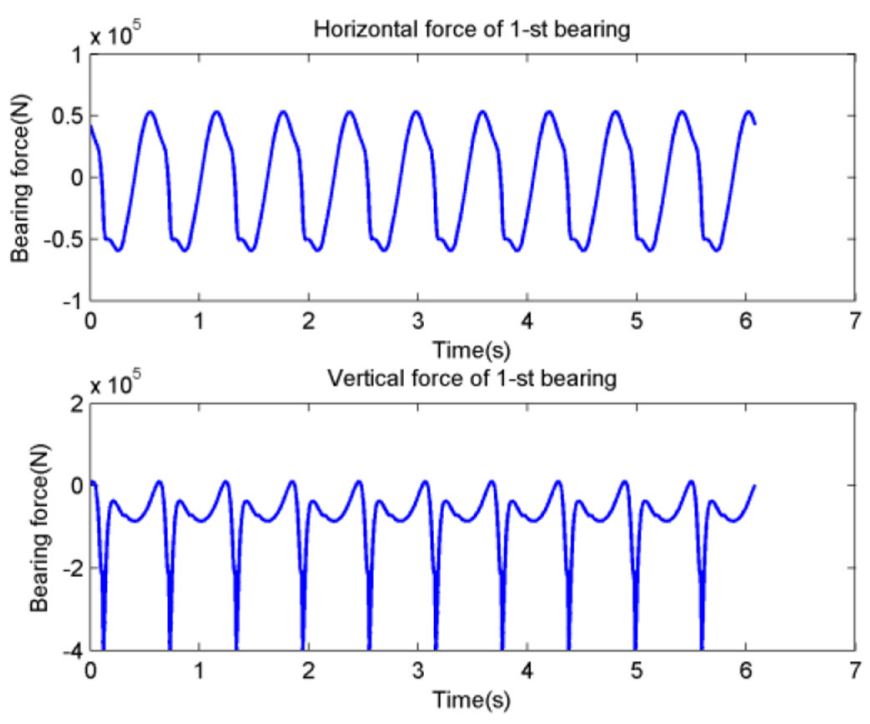

Fig. 5. Main bearing force of 1st bearing.

The loading state of the excitation is changed. Taking the first cylinder as an example, the TDC (Top Dead Center) is assumed as the start time. If the shaft torsional vibration is not considered, the displacement of the crosshead is given as:

$$
x=R(1-\cos \alpha)+L\left(1-\sqrt{1-\lambda^{2} \sin ^{2} \alpha}\right)
$$

where $\lambda=R / L, L$ is the connecting rod length, $R$ is crankshaft radius.

Otherwise, it is given as:

$$
\begin{array}{rl}
x_{t o r} & =R\left(1-\cos \left(\alpha+\theta_{t o r}\right)+\right. \\
L & L\left(1-\sqrt{1-\lambda^{2} \sin ^{2}\left(\alpha+\theta_{t o r}\right)}\right)
\end{array}
$$

The oscillation of loading location, which is the crosshead displacement fluctuation coupled by the torsional vibration, is obtained by subtracting $x_{t o r}$ from $x$. In order to load the real forces of excitation on the FEM, it proposed an additional moment to predict the vibration of engine's block based on the method of force translation. The additional moment is given as:

$$
\begin{gathered}
M_{\text {tori }}=F_{\text {tori }} L_{\text {tori }} \\
F_{\text {tori }}=F_{\text {Hitor }}-F_{H i}
\end{gathered}
$$

where $F_{\text {tori }}$ is the oscillation of side thrust force, $F_{H i t o r}$ is the side thrust force coupled torsional vibration, $F_{H i}$ is the side thrust force in normal condition and $i$ is the cylinder number. $L_{t o r}$ is the oscillation loading location and given as follows:

$$
L_{t o r}=x_{t o r}-x
$$

where $x_{t o r}$ is the displacement coupled torsional vibration and $x$ is the displacement in normal condition. 


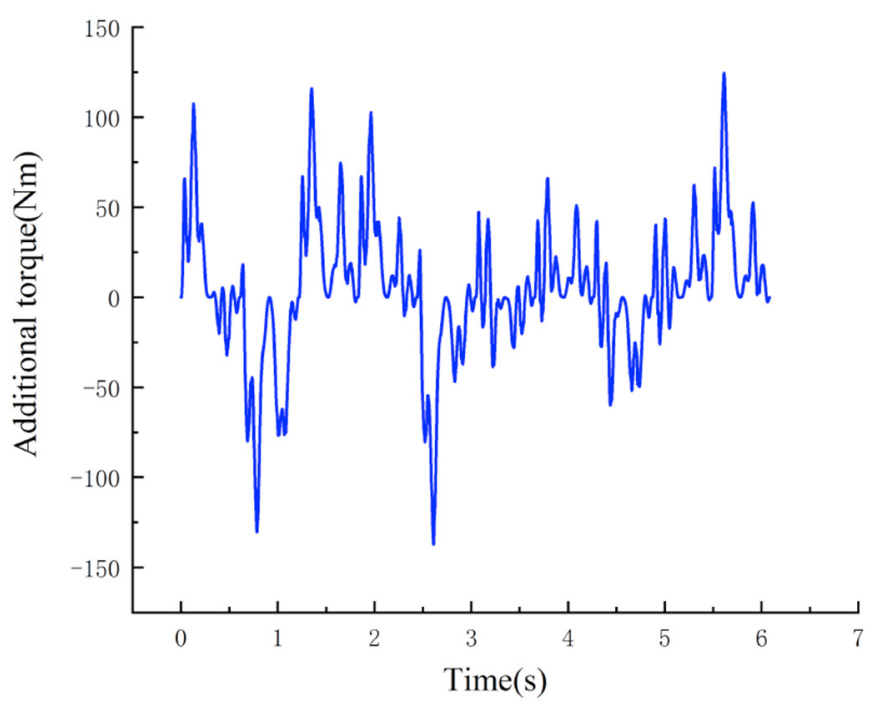

Fig. 6. Additional moment caused by shaft torsional vibration.

From equations $(14)-(16)$, the additional moment is obtained. Using first cylinder as an example the results is shown in Figure 6.

\section{Experiment set-up}

To verify the coupling method predicting the vibration response, the test was conducted on the vibration of engine's block and the torsional vibration of low speed diesel engine.

\subsection{Block model test}

Using B\&K PLUSE and utilizing the single-input and multiple-output technology, the natural modes of engine's block is obtained.

The test pattern with B\&K PLUSE is shown in Figure 7.

\subsection{Block and torsional vibration test}

To verify the predicted results, the speed of diesel engine is $99 \mathrm{rev} / \mathrm{min}$. The power is $1224 \mathrm{~kW}$. The location of four measuring points, the measure system of block vibration and torsional vibration are shown in Figure 8. The measurement of the first to third point are located at the foot of engine. The measurement of the fourth point is located at the middle of the engine block. The measurement of the torsional vibration is located at the flywheel.

\subsection{Instantaneous torsional angle}

Using the sensor of pulse counting, the original square wave signal of the shaft torsional vibration is obtained and shown in Figure 9. In the test, the output signal of the sensor is a frequency-modulated signal modulated by the shaft torsional vibration. This signal can be demodulated by pulse counting method.

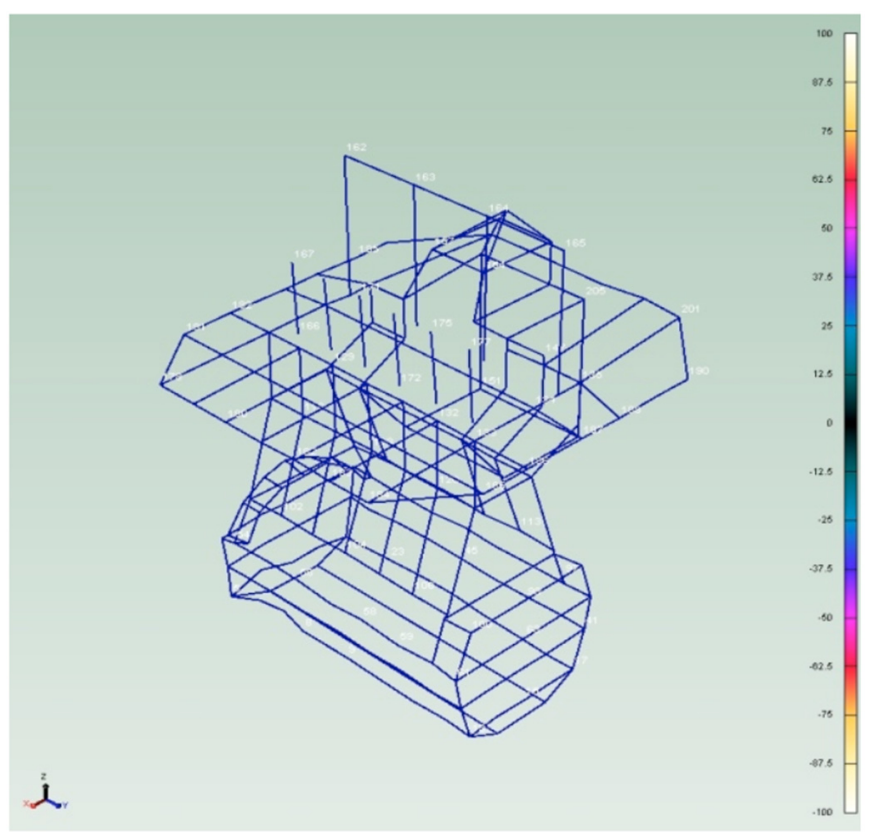

Fig. 7. Free vibration test model of low speed diesel engine in B\&K Pulse.

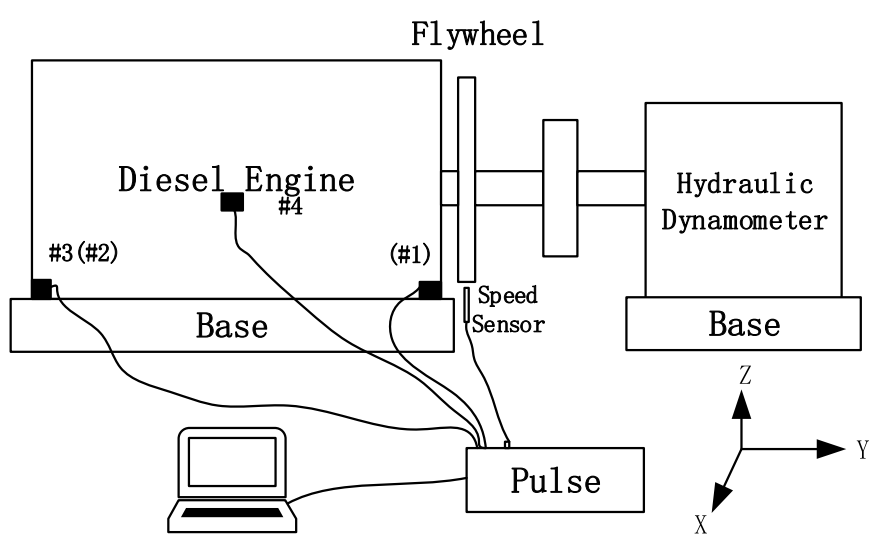

Fig. 8. Measure system of block vibration and torsional vibration.

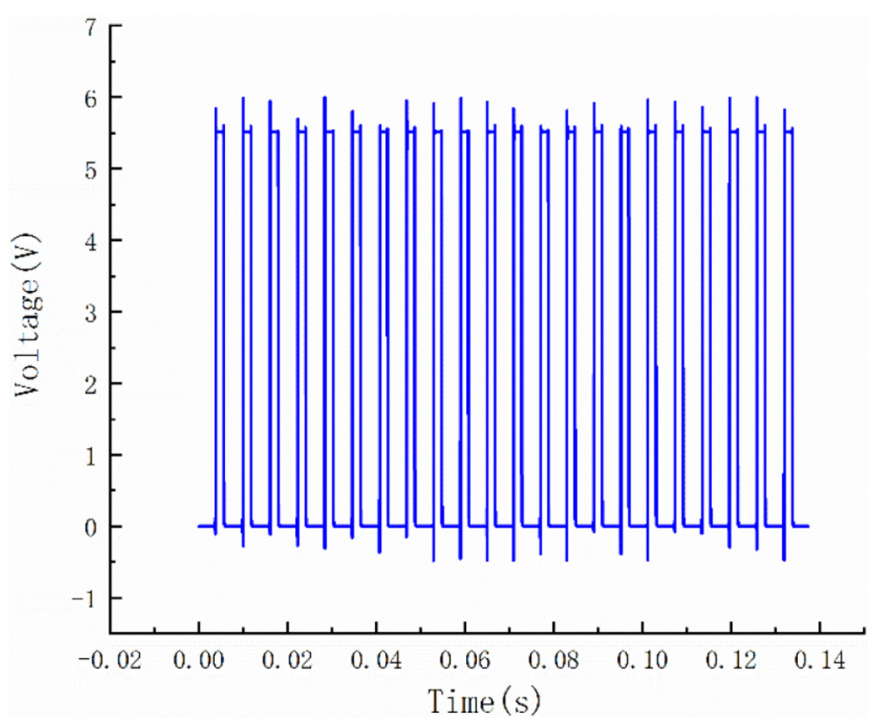

Fig. 9. Original square wave signals of shaft torsional vibration. 


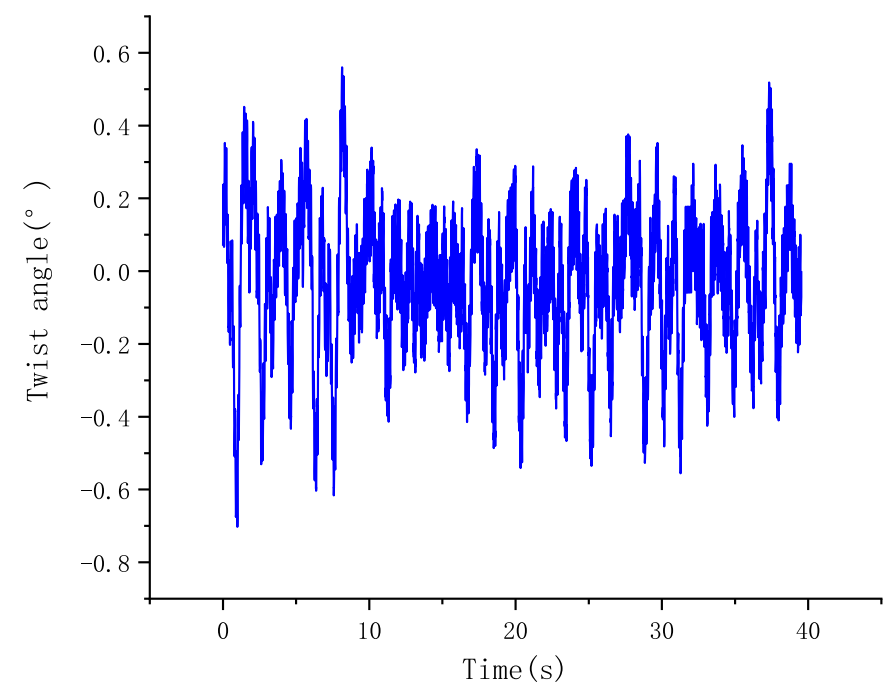

Fig. 10. Measured results of instantaneous torsional angle at flywheel.

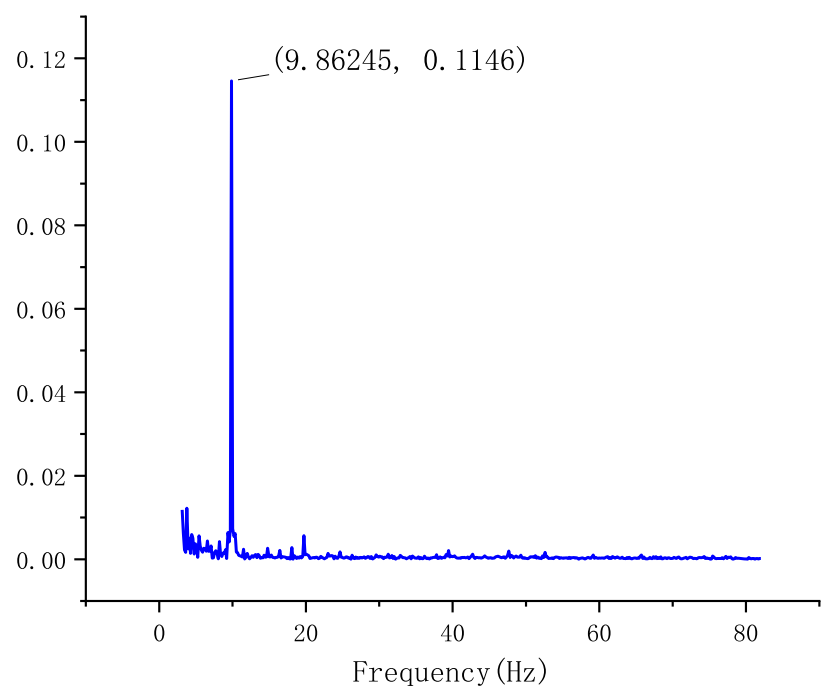

Fig. 11. Measured results of spectrum of torsional vibration at flywheel.

From the test results in Figure 9, the instantaneous torsional angle of the crankshaft is given as following:

$$
\begin{aligned}
\theta_{\text {tor }}(t)= & \int_{0}^{t_{n}}\left(\omega_{\text {in }}-\omega_{c}\right) d t=\left(\frac{\omega_{c} n \frac{t_{c}}{N}}{t_{n}}-\omega_{c}\right) t_{n} \\
& =\frac{360^{\circ}}{t_{c}}\left(n \frac{t_{c}}{N}-t_{n}\right)
\end{aligned}
$$

where $\omega_{i n}$ is the instantaneous angular velocity; $t_{c}$ is the time of the per rotation; $\omega_{c}=\frac{360^{\circ}}{t}$ is the average angular velocity; $N$ is the tooth number of shaft gear; $t_{n}$ is the time to output $n$th pulse signal and $n$ is the number of pulse. $\theta_{\text {tor }}(t)$ is fluctuation of twist angle of each tooth time. The results in time domain and in frequency domain are shown in Figures 10 and 11.

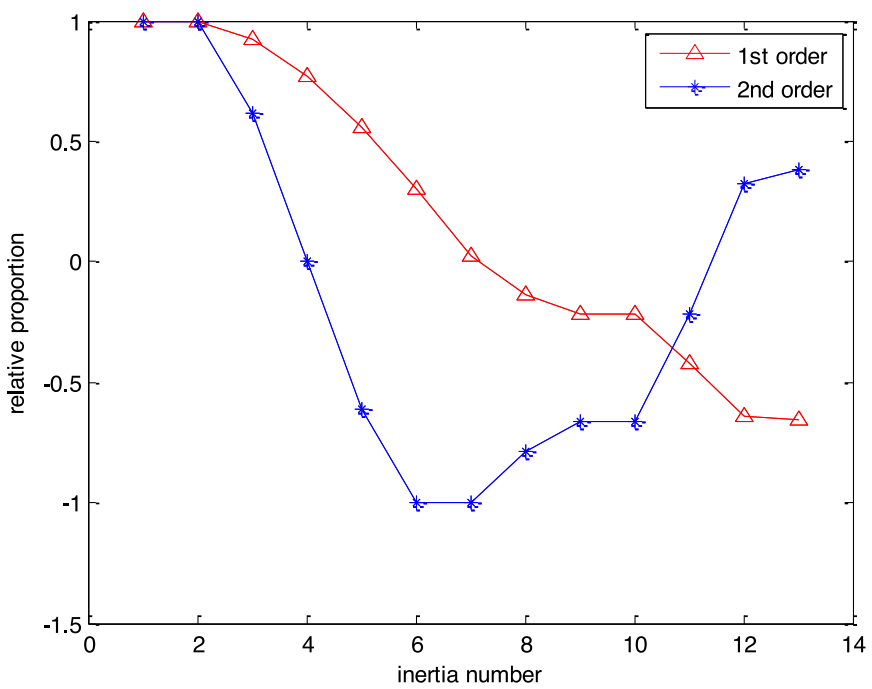

Fig. 12. Mode shape of torsional vibration.

Table 2. Natural frequencies of torsional vibration.

\begin{tabular}{llll}
\hline No. & Test $(\mathrm{Hz})$ & Simulated $(\mathrm{Hz})$ & Difference $(\%)$ \\
\hline 1 & 22.095 & 21.22 & 3.96 \\
2 & 47.311 & 46.67 & 1.35 \\
\hline
\end{tabular}

The instantaneous torsional vibrations in different cylinder are calculated by the measured result at flywheel and the torsional vibration model shape. The torsional vibration model shapes are shown in Figure 12. The natural frequencies of torsional vibration is given in Table 2 .

\section{Validation of the block finite element model and the response}

\subsection{FEM model}

In this section, a FEM model of low speed diesel engine is created to study the influence of torsional vibration on the vibration of engine's block. The created FEM model is shown in Figure 13a. The platform is shown in Figure 13b. The complex structure and the large number of accessory parts are simplified into the following main parts. They are the bed plate, the frame, the cylinder cover, the cylinder body, the upper work platform, the intake and the exhaust system. The bed plate and the frame of low-speed diesel engine are modeled by shell elements. The cylinder body and the cylinder covers are modeled by solid elements. The Upper work platform is modeled by beam elements. The spring elements and the beam elements are used to model of the bolt connection and welding. There are three part boundaries between the FEM and environment namely bed plate and the hull, exhaust pipe and hull, the upper work platform and hull. Using some different elasticity and damping springs are simulated the constraint state of FEM model. The mass and the materials of FEM model are the same 


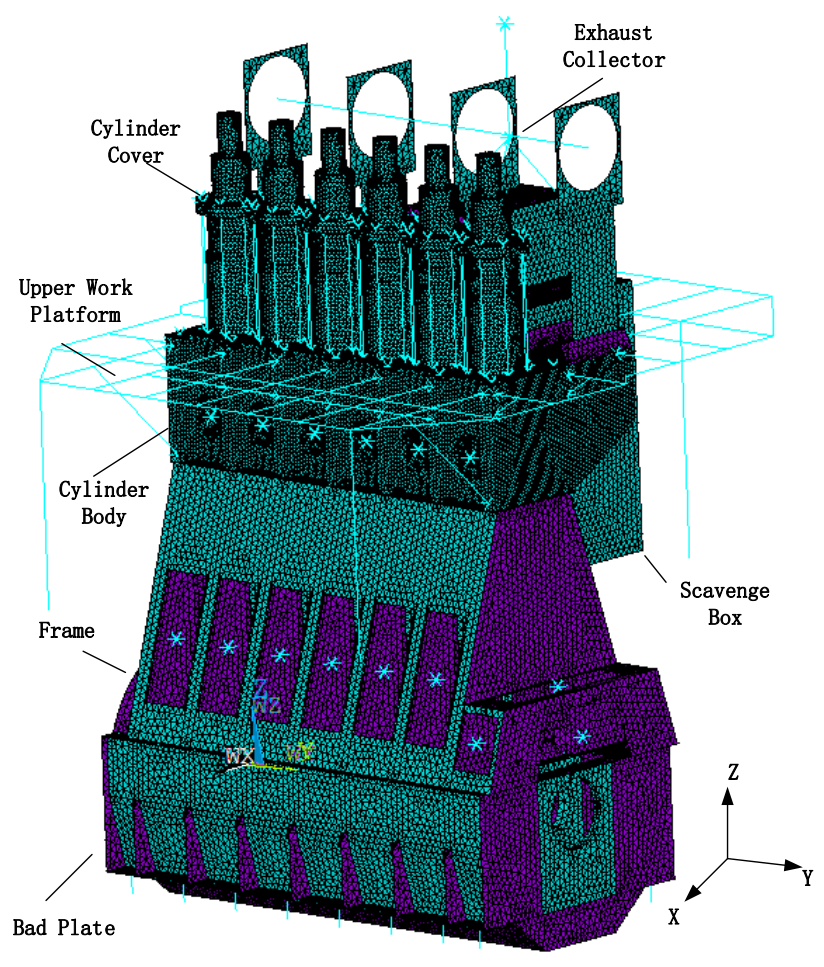

(a)

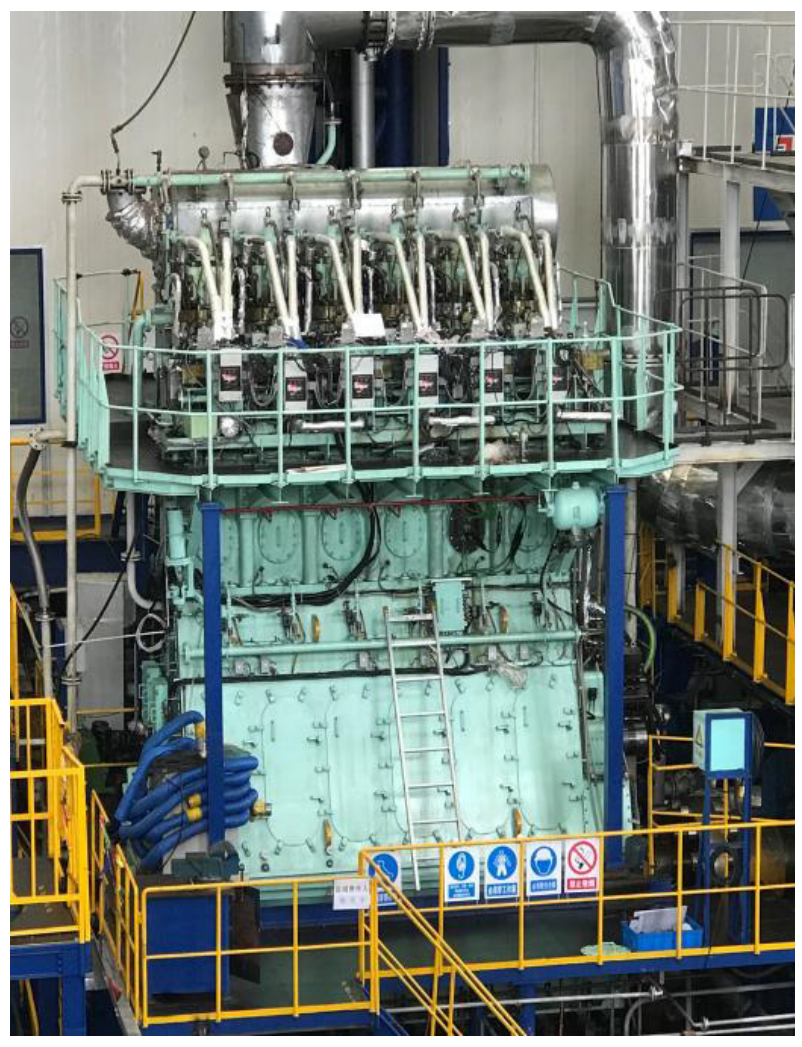

(b)

Fig. 13. Low speed diesel engine. (a) FEM model. (b) Test platform.

Table 3. Natural frequencies comparison with test and FEM.

\begin{tabular}{lclc}
\hline No. & Test $(\mathrm{Hz})$ & FEM $(\mathrm{Hz})$ & Difference $(\%)$ \\
\hline 1 & 13.01 & 13.6 & 4.5 \\
2 & 14.94 & 14.96 & 0.13 \\
3 & & 15.85 & - \\
4 & 21.8 & 20.7 & -5 \\
5 & 26.4 & 26.4 & 0 \\
6 & 33.54 & 32.86 & 2 \\
7 & 45.25 & 45.39 & 0.3 \\
8 & 55.36 & 53.2 & -0.9 \\
9 & 62.19 & 62.18 & -0.02 \\
10 & 73.73 & 74.7 & 1.3 \\
11 & 86.01 & 83.32 & -3.1 \\
12 & 96.43 & 92.8 & -3.7 \\
\hline
\end{tabular}

as the physical structures of low speed diesel engine. The parameters of springs and dampers used in the model are chosen based on design and engineering experiences. The natural frequencies of the test and simulation are given in Table 3. The mode shape are similar between the test and simulation. The result are given in Appendix.

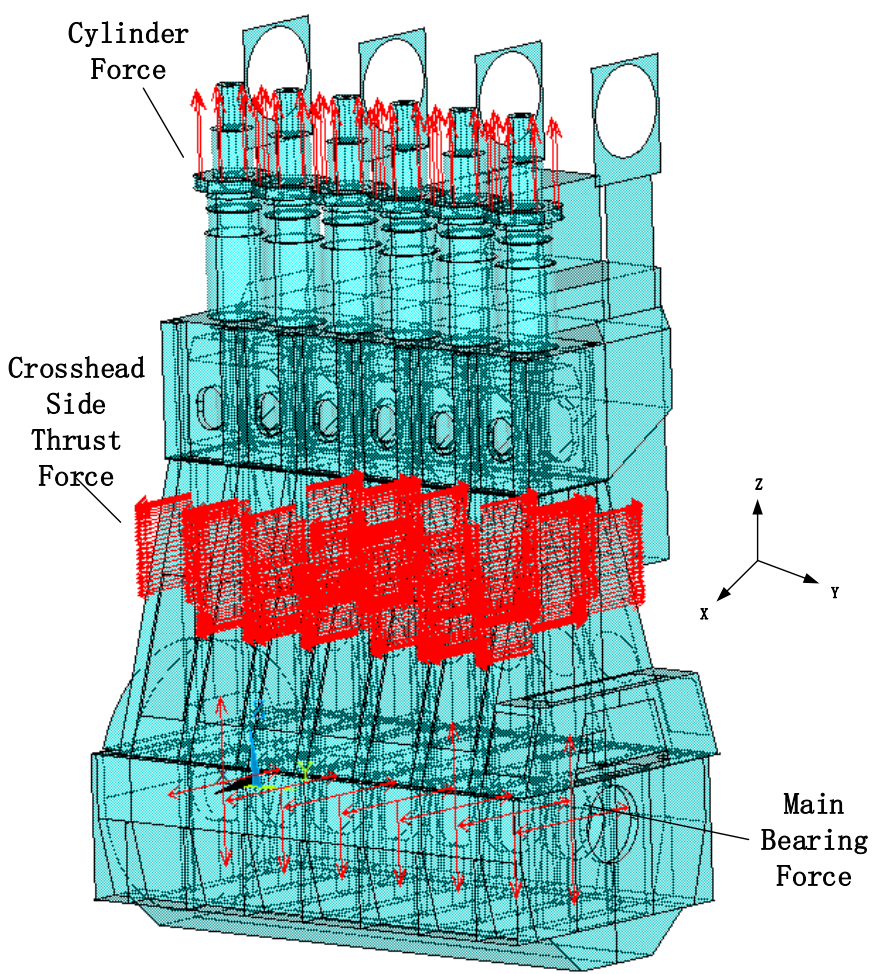

Fig. 14. Excitation loading diagram. 


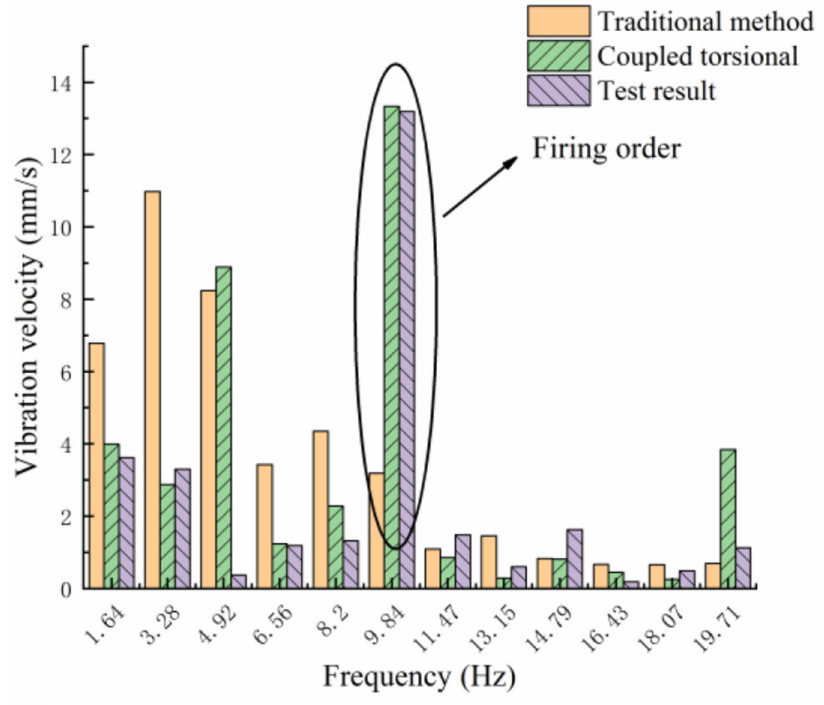

(a)

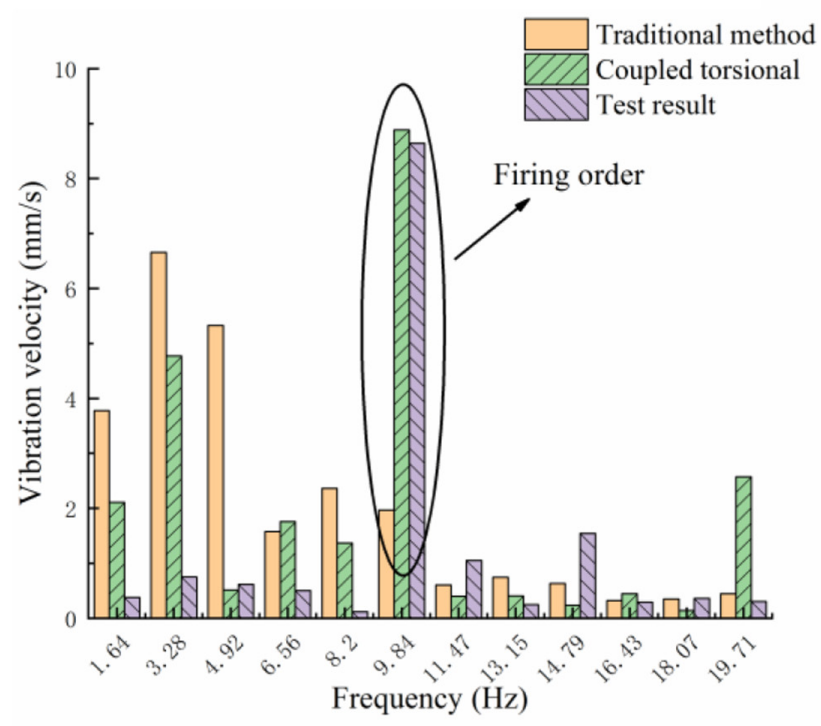

(c)

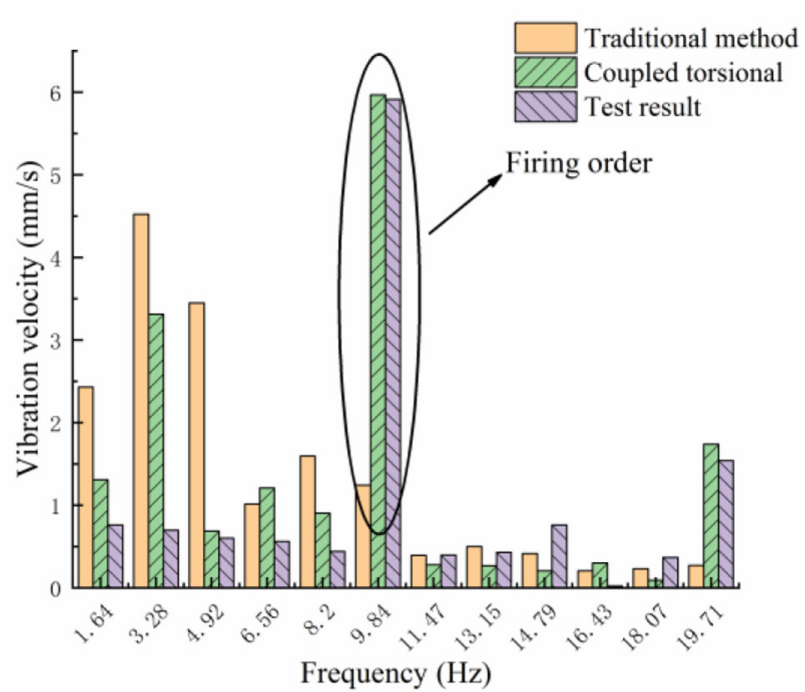

(b)

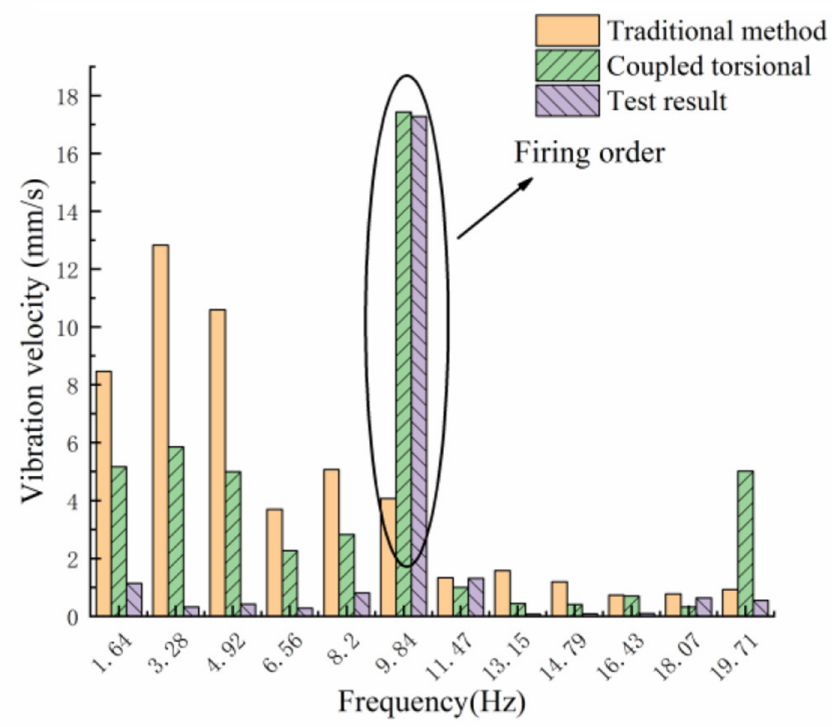

(d)

Fig. 15. Result comparison between test and Simulation. (a) Node 1 vibration response, (b) Node 2 vibration response, (c) Node 3 vibration response, (d) Node 4 vibration response.

The results indicate that the FEM natural frequencies results agree with the test well and the differences between them all are within $5 \%$, which meets the engineering requirement. Hence, the calibrated FEM block model is acceptable to be used in the simulation analysis later on.

\subsection{The results of prediction vibration of block}

In this section, to show the effect of the crankshaft torsional vibration on the block structure vibration of diesel engine, the FEM simulation of block's vibration is carried out under the excitation forces mentioned above. The cylinder force, the crosshead side thrust force and the main bearing forces are loaded at nodes. The cylinder pressure is loaded directly on eight fastening bolts which fixed the cylinder cover to transfer the vibration. For the side thrust of crosshead, its position and direction is changing with the crank rotation and it is loaded on the crosshead guide rail. For the main bearing force, its direction and size is affected by the rotation of the crankshaft, but its position are always in the center of the main bearing. Based on the ANSYS Parametric Design Language in ANSYS, the position and size of the excitation forces are controlled. The excitation loading function is shown in Figure 14. The diesel engine speed is set up $99 \mathrm{r} / \mathrm{min}$. The power is $1224 \mathrm{~kW}$. The max of cylinder pressure is $1.0 \mathrm{e} 7 \mathrm{~Pa}$. 
Table 4. Comparison between measured vibration results and not considering additional moment results

\begin{tabular}{lcll}
\hline Points & Test $(\mathrm{mm} / \mathrm{s})$ & $\begin{array}{l}\text { Non-torsional } \\
\text { vibration }(\mathrm{mm} / \mathrm{s})\end{array}$ & Difference (\%) \\
\hline No.1 & 13.72 & 3.192 & -76.7 \\
No.2 & 6.134 & 1.242 & -79.7 \\
No.3 & 9.009 & 1.965 & -78.1 \\
No.4 & 17.98 & 4.071 & -77.4 \\
\hline
\end{tabular}

Table 5. Comparison between test vibration results and considering additional moment results

\begin{tabular}{lcll}
\hline Points & Test $(\mathrm{mm} / \mathrm{s})$ & $\begin{array}{l}\text { Coupled-torsional } \\
\text { vibration(mm/s) }\end{array}$ & Difference (\%) \\
\hline No. 1 & 13.72 & 13.34 & -2.7 \\
No. 2 & 6.134 & 5.967 & -2.7 \\
No. 3 & 9.009 & 8.883 & -1.4 \\
No. 4 & 17.98 & 17.43 & -3.1 \\
\hline
\end{tabular}

In the traditional method, the torsional vibration effect was not considered in the block vibration prediction. By considering the additional torque caused by the crankshaft torsional vibration, the accuracy of the predicted engine block vibration is improved.

The comparison of the results of $\mathrm{Z}$ direction between test and simulation is shown in Figure 15. The difference of the amplitude of the sixth order which is the great affected by torsional vibration is given in Tables 4 and 5 .

In the condition of engine speed at $99 \mathrm{rev} / \mathrm{min}, 1.64 \mathrm{~Hz}$ is the 1st order frequency. Other peak frequency (such as 2nd order, 3rd order, 4th order et al.) increase in multiples of $1.64 \mathrm{~Hz}$. Due to this diesel engine with six cylinders, the main firing frequency is $9.9 \mathrm{~Hz}$, where the peak value is maximum in the whole spectrum. From Figure 14, as a whole comparison with test results, the results show that considering torsional vibration better than not considered. The prediction accuracy of the amplitude of the sixth order $(9.9 \mathrm{~Hz})$ are greatly improved. The difference of the amplitude of the firing order is given in Tables 4 and 5 .

The results show that for the velocity and the amplitude of the sixth order, the FEM results agree with the test results due to the additional moment caused by the oscillation of the loading position of side thrust. The differences between traditional method and considering torsional vibration show that the shaft torsional vibration does effect greatly on the amplitude of the firing harmonic frequency.

\section{Conclusion}

In this paper, the effect of the crankshaft torsional vibration on the engine block vibration was investigated. Through the simulation and experimental analysis, the main conclusions can be summarized as follows:
- A FEM model of engine block has been established, and the FEM mode results agree with the test well. It proves that the calibrated FEM block model is acceptable to be used in the simulation analysis.

- Compared to the traditional method, the additional moment caused by shaft torsional vibration has been found on the crosshead, which was not considered in the simulation before.

- By considering the additional moment caused by the crankshaft torsional vibration, the accuracy of the predicted engine block vibration is improved. It shows that the crankshaft torsional vibration has an important effect on the engine block vibration.

This research was supported by Marine Low-Speed Engine Project-Phase I and National Natural Science Foundation of China (Grant No. 51805106).

\section{Appendix}

The mode shape of engine block were measured and simulated separately. For the result of 1st order and 2nd order as an example which is shown in Figures A1 and A2.

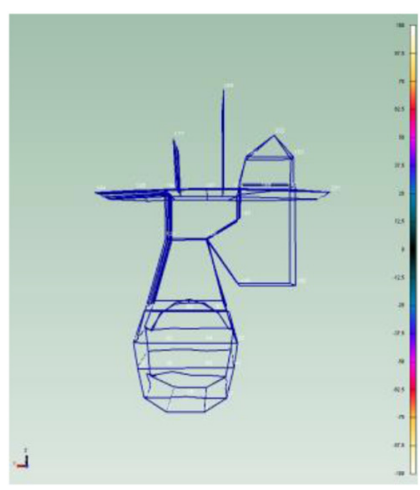

(a)

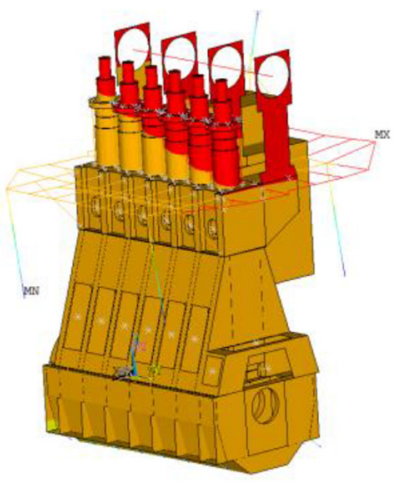

(b)
Fig. A.1. Mode shape at 1st order. (a) Test model. (b) Simulated model.

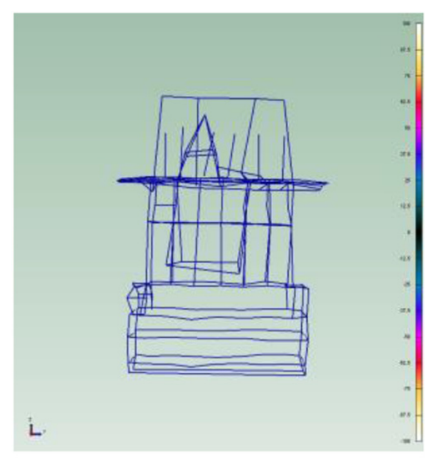

(a)

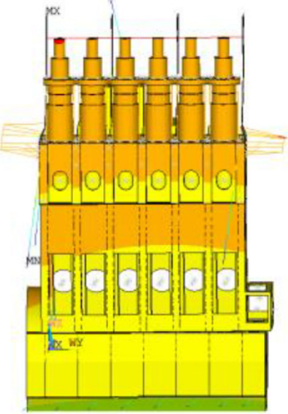

(b)
Fig. A.2. Mode shape at 2nd order. (a) Test model. (b) Simulated model. 


\section{References}

[1] Q. Zheng, Engine dynamic. In: National defense industry press (1986)

[2] H. Zheng, G.R. Liu, J.S. Tao, K.Y. Lam, FEM/BEM analysis of diesel piston-slap induced ship hull vibration and underwater noise, Appl. Acoust. 62, 341-358 (2001)

[3] S. Cho, S. Ahn, Y.H. Kim, A simple model to estimate the impact force induced by piston slap, J. Sound Vib. 255, 229 $242(2003)$

[4] Z. Mourelatos, A crankshaft system model for structural dynamic analysis of internal combustion engines, Comput Struct. 79, 2009-2027 (2001)

[5] O. Ebrat, Z. Mourelatos, K. Hu, N. Vlahopoulos, K. Vaidyanathan, An elastohydrodynamic coupling of a rotating crankshaft and a flexible engine block, J. Tribol. 126, 233-241 (2004)

[6] L. Wei, H. Wei, H. Du, S. Duan, Three-dimensional vibration of the crankshaft of a large marine diesel engine under a mixed thermo-elastic-hydro- dynamic lubrication coupling between flexible crankshaft and engine block, J. Eng. Gas Turb. Power 140, 1-10 (2018)

[7] Z. He, W. Gong, W. Xie, J. Zhang, G. Zhang, Z. Hong, NVH and reliability analyses of the engine with different interaction models between the crankshaft and bearing, Appl. Acoust. 101, 185-200 (2016)

[8] D. Xue, X. Song. Internal combustion engine noise caused by torsional vibration of crankshaft, J. Dalian Univ. Technol. 36, 576-580 (1996)

[9] X. Liang. A study on 3D vibration of the crankshaft and structure vibration of the crankshaft based on partial coherence function analysis. Automot. Eng. 28, 271-275 (2006)

[10] X. Liang, Research on noise control and prediction of sound radiation for I.C. engines ( $\mathrm{PhD}$ Thesis), Tianjin University. 2006

[11] X. Duan, Study on the influence of torsional vibration on cylinder block vibration, I.C.E. Power Plant 5, 23-36 (2009)
[12] D. Wang, Research on vehicle vibration excited by torsional vibration of the powertrain (M.S. Thesis), Southwest Jiao Tong University. 2015

[13] Y. Li, Z. Hao, Influence of the crankshaft torsional vibration to force of bearing and noise radiation of the engine, J. Mech. Electr. Eng. 35, 443-449 (2017)

[14] Y. Li, Research on influence of crankshaft and timing systems dynamic characteristics on engine NVH performance (M.S. Thesis), Zhe Jiang University. 2012

[15] M. Inagaki, A. Kawamoto, T. Aoyama, K. Yamamoto, Prediction of structural and kinematic coupled vibration on internal combustion engine, Res. Report 37, 27-33 (2002)

[16] Z. Ma, N. Perkins, An efficient multibody dynamicas model for internal combustion engine systems, Multibody Syst. Dyn. Kluwer Acad. Publ. 10, 363-391 (2003)

[17] J. Zhang, J. Han, CAE process to simulate and optimise engine noise and vibration, Mech. Syst. Signal Process. 20, 1400-1409 (2006)

[18] C. Cameron, P. Wennhage, P. Göransson, Prediction of NVH behaviour of trimmed body components in the frequency range 100-500 Hz, Appl. Acoust. 71, 708-721 (2010)

[19] K. Ohta, K. Ikeda, G. Zheng, T. Okimoto, I. Honda, Vibration response and noise radiation of engine block coupled with the rotating crankshaft and gear train, Nihon Kikai Gakkai Ronbunshu, C Hen/Transactions Japan Soc. Mech. Eng. Part C. 75, 789-795 (2009)

[20] K. Ohta, K. Ikeda, T. Futae, Study on the noise and vibration of engine block coupled with the rotating crankshaft and the gear train; effect of the torsional vibration of crankshaft, In: 20th International Congress on Sound \& Vibration, 7-11 (2013)

[21] D. Lee, S. Kim, R.D. Barro, A case study of thrust variation force due to coupled torsional axial vibration on two stroke low speed diesel engines, In: 24th International Congress on Sound and Vibration, 23-27 (2017)

Cite this article as: S. Ni, Y. Guo, B. Lv, D. Wang, W. Li, Z. Shuai, Analysis of torsional vibration effect on the diesel engine block vibration, Mechanics \& Industry 21, 522 (2020) 